\title{
La autoconciencia y el poder del Selbst como reconocimiento necesario
}

\author{
JOSÉ MANUEL SÁNCHEZ FERNÁNDEZ \\ Universidad de Castilla-La Mancha
}

\section{INTRODUCCIÓN}

El presente trabajo planteará tres aspectos fundamentales de la Figura de la Autoconciencia, resaltando la vigencia y el papel que juega en la Fenomenología del Espíritu de Hegel. Dicho propósito se desarrolla en los tres apartados siguientes:

I La posición y la disposición de la Autoconciencia dentro de la estructura del Saber hegeliano.

II Los dos motores que impulsan a la Autoconciencia: el anhelo (Begierde) y la contraposición (Gegensatz).

III Finalmente, estudiaremos el fenómeno fundamental que se desprende de la Autoconciencia: el reconocimiento (Anerkennung) en relación con su expresión más adecuada en el Selbst (sí-mismo) o interioridad.

\section{POSICIÓN Y DISPOSICIÓN DE LA AUTOCONCIENCIA: \\ EL SALTO INFINITO DE LA REALIDAD.}

Los tres primeros capítulos de la Fenomenología del Espíritu (Certeza, Percepción y Entendimiento) presentan a la Conciencia como la figura inaugural en la que se imprime movimiento a lo real. Una vez desarrollado dicho movimiento y puesto en marcha como exteriorización llega hasta el umbral de la Autoconciencia, donde hace quiebra desde sus propios cimientos. La diferencia fundamental entre las dos primeras figuras mencionadas se produce respecto de su contenido que, si bien atañe al ser-uno de la realidad en la Conciencia, se realiza, sin embargo, frente al ser-otro en la Autoconciencia ${ }^{1}$. El movimiento

1 La traducción al castellano del término Begierde por "anhelo" implica el movimiento de una voluntad personal y no de un simple deseo (que sería begierig), ya que su sentido concreto es "avidez". El concepto de movimiento que surge en la Autoconciencia emerge desde una perspectiva paradójica que Römmp señala acertadamente: "La paradoja admite ya el carácter de un 
que se lleva a cabo como tránsito de la Conciencia a la Autoconciencia refleja el traspaso de la barrera del conocimiento (Erkennen), como sucede en la precedente y se instaura de modo esencial como reconocimiento (Anerkennung) ${ }^{2}$ en la siguiente. El itinerario expositivo que seguimos toma como punto de partida y referencia obligada, la interpretación que hace L. Siep respecto del término "reconocimiento" (Anerkennung). Este concepto juega un papel orientador básico de los capítulos IV, V y VI de la Ph.d.G, en los que Hegel desarrolla las figuras de la Autoconciencia, la Razón y el Espíritu, respectivamente. Siep ha investigado los orígenes del término Anerkennung en los escritos de Jena 1801-1805 (el Naturrechtsaufsatz y el System der Sittlichkeit) y ha encontrado una aplicación ulterior a la Filosofía del Espíritu que abarca tanto la citada Fenomenología de 1807, como los escritos posteriores de Berlín. Nos referimos a la Filosofía del Derecho y a la Enciclopedia.

El contenido de la Autoconciencia descansa en la concepción de "reconocimiento" que Hegel prefigura en Frankfurt y concreta con mayor precisión conceptual en Jena. Pero el origen remoto que configura el sentido filosófico al "reconocimiento" se encuentra en la obra de Hobbes bajo la máscara de la violencia (potestas) o poder coercitivo del Estado frente a los individuos. Este término evoluciona con el tiempo hasta que Fichte lo aplica posteriormente a la fundamentación del Derecho natural ${ }^{3}$. Ambos autores constituyeron la base

movimiento, en la que dos Autoconciencias que existen (seiende) en una relación (Verhältniss) para-sí y para nada, pierden los estribos [se desatan] al ser la inseparable acción del uno, la acción del otro". Römmp, G. "Ein Selbstbewusstsein für ein Selbstbewusstsein". Hegel Studien no23 (1988), pp. 71-94. (p.82).

2 A este respecto véase en especial: Siep, L. Anerkennung als Prinzip der praktischen Philosophie, Karl Alber (1979), pp.210-223, y el artículo "Zur Dialektik der Anerkennung bei Hegel”. Hegel Jahrbuch (1974), pp.388-395 y "Der Kampf um Anerkennung. Zu Hegels Auseinandersetzung mit Hobbes in den Jeaner Schriften”. Hegel Studien n ${ }^{\circ}$ 9, (1974), pp.155-207. En este sentido, Siep comenta: "Por método Hegel entiende aquí: el movimiento necesario de la 'cosa', del espíritu que se representa y se reconoce en el elemento de la conciencia natural. Una tal concepción de método presupone -o extiende el ejemplo- que la cosa y su conocimiento son idénticos, o que la diferencia entre conocimiento y ser puede ser sobrepasada a cambio de su identidad absoluta". Siep (1979), op. cit., p.332. Römmp matiza este comentario: "Este giro se desarrolla en favor del concepto de reconocimiento (Annerkennens) que, acorde con nuestra posición, expresa en la Fenomenología del Espíritu la determinación estructural de más amplio desarrollo de la relación de la Autoconciencia, con la ayuda de la temática del dominio y la Esclavitud". Römmp (1988), art. cit., p.83

3 Fichte, J.G. Gesammtausgabe. BAdW. Lauth, R. y Jacob, H. Ed. Friedrich Frommann, Stuttgart-Bad Cannstatt (1966). Grundlage des Naturrechts nach Principien der Wissenschaftlehre. Werke I,3. 1794-1796. En especial las pp.319, líneas 20-30 y 322, líneas 8-9, donde Fichte aclara los principios del Derecho natural a la luz de la Doctrina de la Ciencia. A este respecto hemos de añadir el trabajo de E. Nowak-Juchacz "Das Anerkennungsprinzip bei Kant, Fichte und Hegel”. Fichte Studien n²3 (2006), pp.75-84. 
sociológico-especulativa que Hegel utilizó expresis verbis para desarrollar, dentro del marco de la Ph.d.G., una teoría completa del reconocimiento.

El intento de síntesis de la posición (Stimmung) y de la ulterior disposición (Bestimmung) de la Autoconciencia dentro de la estructura del saber hegeliano, implica el desarrollo del reconocimiento desde dos momentos fundamentales: a) en cuanto al papel que desempeña el contenido de dicha figura, el cual se encuentra duplicado (hecho que constituye su posición) e impide su salida fuera de sí misma y, b) ante el carácter infinito de dicho contenido. En este sentido, la Autoconciencia desarrolla su contenido como interioridad, lo cual nos obliga a movernos de un modo paradójico por el reino de la libertad ${ }^{4}$ o del Ser para-sí que delimita su acción. La realidad de la Autoconciencia se construye sobre la base de un contenido infinito, el cual determina un campo y un sentido autorreferenciales ${ }^{5}$ para ella.

La referencia que se produce, por tanto, en el ámbito de la Autoconciencia entre las realidades subjetiva y objetiva se establecerá como una construcción de planos de realidad divergentes, escindiendo su contenido y presentándolos como términos irreconciliables. Los momentos de lo subjetivo y lo objetivo se encuentran separados al modo de "realidades polares" en base a un contenido infinito, cuya complejidad expresa la multiplicidad y la riqueza que suceden en el interior de la Autoconciencia:

"La Conciencia tiene ahora como Autoconciencia un doble objeto, el primero inmediato, el objeto de la Certeza sensible y de la Percepción, pero que está señalado por ello con el carácter de lo negativo; y el segundo, que es en efecto sí

4 "Una Conciencia, que se piensa como infinitud (Unendlichkeit) o como movimiento puro de la Conciencia es la esencia o la Autoconciencia libre". G.W. 9 (Phä), p.116, líneas 2527. A este respecto la interpretación de Gloy se hace imprescindible: "La libertad permanece únicamente en el interior de la esclavitud que carece del reconocimiento libérrimo a través del Amo. También la esclavitud interna más libre no constituye sociedad alguna recíprocamente a la esencia racional libre que se reconoce". Gloy, K. "Bemerkung zum Kapitel "Herrschaft und Knechtschaft' in Hegels Phänomenologie des Geistes". Zeitschrift für Philosophische Forschung 39:2 (1985:Apri/Jun), pp.187-213. (p.196).

5 "De este modo se establecerá primeramente la determinación por la vida o, dicho con exactitud: para la autorreferencialidad del círculo de la vida, que la Autoconciencia pone frente a ella como Ser Para-sí subjetivo autorreferente. Las estructuras del dominio y de la servidumbre se señalan, por un lado, en la autorreferencialidad de la vida, que es de igual modo para-otro, en efecto para el puro Para-sí y, por otro lado, en el Para-sí es el puro Selbstsein, sin ser para otro y depender así del otro (aunque tenga referencia al otro)". Gloy (1985), art. cit., p.210. Además, añadimos el siguiente comentario de Römmp: "El movimiento interno del Saber que se fundamenta en la ciencia no nos conduce a una deducción sistemática del no-yo y de su disposición (Verfassheit) categorial, sino a una teoría de la interpersonalidad que puede reclamar interés y, por otro lado, ser significativamente decisiva para el desarrollo ulterior de la 'ciencia de la experiencia de la conciencia"”. Römmp (1988), art. cit., p.73. 
mismo, la esencia verdadera y sólo ha existido primeramente en contraposición con el primero" 6 .

Autoconciencia (Selbst-Bewusstsein) significa aquí un tipo de realidad que debido a su doble carácter marcado, en primer término, por la constitución interna de que se compone y, en segundo término, por la acción externa que surge de ella, se encuentra sometida siempre a una pugna constante por su reconocimiento. De hecho, el reconocimiento se prefigura como el momento articular y núcleo resolutivo de la Autoconciencia, al mismo tiempo que es también el principio explicativo de la realidad de la Conciencia.

\section{LOS MOTORES DE LA AUTOCONCIENCIA:}

EL ANHELO Y EL RECONOCIMIENTO.

Como hemos anticipado en el apartado anterior, la compleja estructura de la Autoconciencia requiere de un análisis pormenorizado de los distintos estratos que la componen, además de una aclaración de cómo éstos afectan a su realidad. Por este motivo, podemos decir que hay dos motores internos que impulsan $^{7}$ a la Autoconciencia: a) el anhelo (Begierde) ${ }^{8}$, impulso esencial y b) la contraposición (Gegensatz) $)^{9}$ que se produce entre la Sustancia infinita, la cual configura al Ser para-sí, y la Sustancia universal, a la que hace referencia como abstracción fundamental, puesto que su origen ontológico se encuentra en el Absoluto. De este modo, la Autoconciencia es deudora de una doble condición: la obligación de vincularse con el ser-múltiple de la realidad y la que se reconoce, respecto de su contenido, como infinita.

a) El anhelo (Begierde) impulsa, en primer lugar, el desarrollo autónomo

$6 \quad$ G.W. 9 (Phä), p.104, líneas 24-29.

7 "Pero esta unidad como la hemos visto es repulsión (Abstossen) de sí misma y este concepto se escinde de lo contrario de la Autoconciencia y de la vida. Aquél es la unidad para el que es la unidad infinita de la distinción, aunque este sea sólo esta unidad misma, que no es al mismo tiempo para sí misma”. G.W. 9 (Phä), p.105, líneas 2-6.

8 "Pero esta contraposición (Gegensatz) de su fenómeno y de su verdad tiene sólo la verdad (...) [y] ésta ha de ser esencial, es decir, Anhelo principalmente" G.W. 9 (Phä), p.104, líneas 21-24. A este respecto nos interesa el punto de emergencia del anhelo: "Primero parece sorprendente que Hegel identifique el objeto de la Autoconciencia desarrollado de este modo como vida, que es el Otro interno en tanto que suyo negativo y que identifique al objeto del anhelo inmediato con lo vital (Lebendiges) (...) En tanto que se comprende como anhelo, es sólo cierto de sí mismo a través de la superación de su objeto interno, como su momento independiente, es decir, a través de la superación de la vida independiente o su Otro interno. Aunque de este modo, se supera a sí mismo como Autoconciencia en la estructura del anhelo". Römmp (1988), art. cit., p.75 y 78 .

9 "En el primer momento es la figura que existe; como ser que es para-sí (fürsichseiend), o en su determinación (Bestimmtheit) aparece la sustancia infinita frente a la sustancia universal". G.W. 9 (Phä), p.106, líneas 8-9. 
de cada uno de los polos que constituyen la Autoconciencia y los alienta a que se relacionen con la realidad que se encuentra más alejada de ellos: la de su contrario (Gegensatz) ${ }^{10}$. El anhelo es el acicate e impulso (Trieb) que fundamenta, por ejemplo, las relaciones entre amo y esclavo, cuya referencia mutua (Beziehung) comporta el deseo del contenido del contrario. No existe una distancia más larga, ni una relación más abrupta que la producida entre elementos irreconciliables y separados por un contenido infinito. Por ello, la Autoconciencia es esencialmente relación (Verhältniss). Adquirir dicho contenido implica que la acción de uno de los términos suprima irremediablemente la del otro por medio del trabajo, además de la dominación (Gewalt). Ambas soluciones, el trabajo y la dominación, constituyen los únicos puntos de fuga y el intento de exteriorización de una figura caracterizada precisamente por todo lo contrario: por atenerse a un contenido que es esencialmente interiorización (Innerung) ${ }^{11}$. En efecto, en esta figura lo que predomina es la disimetría por encima de su equilibrio resolutivo, al menos en su fase inicial, hecho que implica una desigualdad constitutiva desde el mismo momento en que se inaugura. Dicho en otros términos, la Autoconciencia no encontrará nunca equilibrio en su fuero interno, ni podrá gozar de tranquilidad alguna en él. Por este motivo, nuestra polémica figura resuelve su contenido en falso, puesto que no permite siquiera una exteriorización efectiva, bloqueando todo intento de resolverla al margen del enfrentamiento. La Autoconciencia lleva a cabo, sin embargo, la única resolución posible en su interior a través de la dialéctica del amo y el esclavo ${ }^{12}$.

10 Gloy maneja en este punto el análisis que W. Becker lleva a cabo en "Hegels Dialektik von Herrn und Knecht". Hegel Studien Beiheft n 11 (1974), pp. 429-439. Gloy construye su argumentación como crítica a la posición pretérita: "En tanto que la identidad absoluta se afecta de lo contrario, adquiere ella misma el carácter de Autoconciencia. Dado que esto es siempre para Hegel yo empírico, separa [la identidad] en la figura del anhelo [y] hace alusión a la relación de medida esencial (wesensmässig) de la negación del objeto en cuanto a la contrariedad (Gegensätzlichen) sobre ella, de la que se ha afectado". Gloy (1985), art. cit., p.200.

11 "Entonces el En-sí, o el resultado universal de la relación (Verhältniss) del entendimiento en el interior (Innern) de las cosas es la distinción de lo no-distinguible, o la unidad de lo distinguible”. G.W. 9 (Phä), p.104, líneas 38-39 y p.105, líneas 1-2. Gloy añade que la problemática establecida con respecto a la Autoconciencia juega el doble papel de las relaciones exteriorización-interiorización: "[Primera vertiente] el cuestionamiento de una teoría de la intersubjetividad con dos Autoconciencias externas o bien [la misma teoría] pero con dos Autoconciencias internas, así como una fusión de la una en la otra (de la primera en la última) y, [Segunda vertiente] el cuestionamiento de la relación de la estructura típica ideal y de la aplicación (Anwendung) concreta, esto es, de la teoría pura y abstracta o, por el contrario, de la teoría empírica aplicada". Gloy (1985), art. cit., p.200.

12 La determinación "enfermiza" de las relaciones de fundamentación de la dialéctica del amo y el esclavo nos muestra cómo surge de su interior una consideración muy particular del Derecho y de su vinculación con el Estado. Ottmann nos aclara: "Hegel ha comprendido la 
b) La contraposición (Gegensatz) es la tendencia, movimiento o conjunto de las relaciones que se establecen al nivel de la Sustancia y que constituyen, por ende, el ser-múltiple de la realidad. A tenor de las relaciones sustanciales y, más en concreto del largo proceso de determinación del contenido preciso de la Autoconciencia, sobre todo en su vinculación con la estructura del Saber absoluto, se desprenden dos nociones de importancia ontológica: 1) el núcleo generativo de la multiplicidad, y 2) el carácter abstracto de su experiencia, que sólo se concreta en realidades enfrentadas. La determinación del contenido de la Autoconciencia se produce a partir de la contraposición básica entre la Sustancia infinita ${ }^{13}$, que es el contenido de la figura, y la Sustancia universal ${ }^{14}$ de la que depende su origen Absoluto. El Ser-infinito, el Ser que se reconoce como agente de la realidad, se implica en el desarrollo del contenido de la figura de la Autoconciencia por medio de la construcción de la estructura del Para-sí. Dicha estructura se convierte en una región de la realidad en la que habitan elementos tales como la libertad, la verdad de-sí (bajo la máscara de la certeza) y el deseo. Todos estos elementos configuran un estado de enfrentamiento e irresolución, cuya cara visible se manifiesta a través de la lucha de los contrarios entre sí.

La explicación de este estado de pugna consiste en que cada "yo" anhelante, que es el objeto propio de la Autoconciencia, busca satisfacer sus necesidades de un modo absoluto y, por tanto definitivo, tomando tan sólo al contrario como

dialéctica de 'Dominio y Esclavitud' con respecto a la Fenomenología del Espíritu, como una versión de aquel lugar que en el moderno Derecho natural (Naturrecht) se aplicaba como 'Estado natural' (Naturzustand) para la fundamentación del Derecho y del Estado (Staat). Este 'Estado natural' tiene para Hegel una significación histórica; no se identifica ni con los estado feudales, ni con los burgueses, sino sólo con los 'esclavos'. Ya que [dicho estado esclavo] juega, para Hegel, el papel de tránsito de las relaciones naturales (Naturverhältnissen) a la formación estatal (Staatbildung) principal; por lo que no es el modelo de legitimación fundamental para el Derecho y el Estado". Ottmann H. "Herr und Knecht bei Hegel. Bemerkung zu einer missverstandenen Dialektik". Zeitschrift für Philosophische Forschung 35:3/4 (1981:July/Dec), pp.385-94. Art. cit., p.368.

13 "Por contra, la infinitud verdadera se estructura de tal modo que encierra lo finito como su contrario y representa así la unidad de infinitud y finitud. Pensar esto es sólo posible a fuerza de una autodirección de lo infinito, de una 'exteriorización' (Hinaustretten) en su antagónico (Gegenteil), es decir su Alteridad (Andersheit) que se supera, sin embargo, una vez más en la infinitud expansible, basada en una autodirección". Gloy (1985), art. cit., p.202.

14 "Todos los capítulos pasan por la infinitud de momentos dados en su tensión de universalidad y simplicidad. En el primer capítulo sobre 'la certeza sensible' sucede en la tensión entre el Esto (yo, aquí, ahora) y lo universal. Precisamente, con el término indicativo 'Esto' se señala correspondientemente la simplicidad, la individualidad, lo determinado y, de este modo, la reflexión teorética-conceptual que valida el término para toda la simplicidad sin distinción inaprensible, en tanto que cada simplicidad puede ser denominada como un 'esto'. De hecho, el término se muestra como [conteniendo] la mayor Universalidad”. Gloy (1985), art. cit., p.202. 
instrumento o herramienta que le lleva a culminar dicha tarea. Este momento de egoísmo absoluto es necesario, puesto que colabora en la afirmación del "Yo" que reside en la Autoconciencia como una abstracción fundamental de sus propios deseos y necesidades. Dicho de un modo más refinado: la Autoconciencia se compone de un Yo que es deseo puro y desmedido, ante el cual su propia acción se establece siempre por encima de los demás "yoes" a los que anula, apropiándose de una acción y de una libertad que le son ajenas, por medio de la violencia del "dominio". En este sentido, la Autoconciencia no puede hacer otra cosa que luchar contra lo que le rodea, teniendo en cuenta que no se diferencia respecto de las "otras" Autoconciencias más de lo que es esencialmente ella misma.

La problemática del reconocimiento adquiere un carácter propio de resistencia cuando la Autoconciencia ejercita la pretensión desmedida de abarcar toda la realidad, al establecerse como la única acción infinita y legítima frente al resto de las que la rodean. De este modo, surge una paradoja respecto de la cantidad de Autoconciencias que residen en el fuero interno de una figura tan singular en su forma, como infinita en su contenido.

IV. El RECONOCIMIENTO: A LA BÚSQUEDA DEL Sí-MISMO (SELBST).

El movimiento de reconocimiento se efectúa, en primer término y de un modo más básico, en el Yo que está mediado en sí mismo, es decir, que se expresa como vida o deseo. El rótulo inaugural de la Autoconciencia advierte desde su expresión "Verdad de la Certeza de sî" e infiere de ella que dicho elemento (el Yo mismo), no asumirá la función de instancia pura, ni su contenido responderá a una instancia arquetípica. Por el contrario, su papel consiste en establecer una relación esencial con otros "yoes" con los cuales se enfrenta:

"Cierta de la negación (Nichtigkeit) de este otro, [la vida] se ubica para sí misma como su verdad, niega al objeto independiente y produce por esto la certeza de sí mismo como una verdadera certeza, tal y como es ella misma de modo objetual" 15 .

En la Autoconciencia el proceso de satisfacción es interno. Recordemos las palabras de Hegel: "La Autoconciencia alcanza su satisfacción sólo en otra Autoconciencia" ${ }^{16}$. Este hecho que podríamos denominar de autosatisfacción (o referencia interna) complica las relaciones polares de la Autoconciencia ya que: 1) nunca existe una satisfacción completa porque alcanzarla supondría eliminar la referencia mediante su asimilación, y que 2) dicha eliminación 
implica una "lucha constante por el reconocimiento"17. Ambos movimientos desarrollan una estructura compleja que determina las ulteriores relaciones de reciprocidad del propio Selbst en elementos tan importantes como son el retorno y la reconciliación, propios de figuras más "elevadas" como las del Espíritu, la Religión y el Saber absoluto:

"Lo que la Autoconciencia distingue de sí como seiend [ser que existe], en tanto que se ha establecido [como tal] seiend, tampoco tiene en él completamente el modo de la Certeza sensible y de la Percepción, sino que él es en-sí Ser-reflejo (reflectiertes Sein) y el objeto del anhelo inmediato es algo vital (lebendiges)" $"$.

Precisamente, el carácter vital que tiene la Autoconciencia, su resistencia frente a la realidad de lo-otro que es su enemigo esencial, hace posible la superación de su contenido y la disolución de su contradicción interna. Ambos hechos producen un efecto de gran utilidad: la resolución de la Autoconciencia a través de su disolución interna.

El contenido de la Autoconciencia se resuelve en tres pasos consecutivos que constituyen su movimiento interno o dialéctica. En el primero de ellos se produce la pérdida de realidad del Selbst que se enajena en su contrario, en un movimiento de tipo negativo. Cada uno de los elementos de la Autoconciencia, polarizados en lo-uno y lo-otro de sí misma, se niegan a sí mismos en un intento de reflejarse en su ser-otro. Al no conseguirlo, la Autoconciencia tiende a asimilar el polo contrario y eliminarlo. En segundo término, se realiza la acción positiva que es el momento de la "superación" (Aufhebung). Sólo cuando la Autoconciencia se da cuenta de que su acción es esencialmente acción del otro y que no difiere nada de él, comienza el lento aunque exitoso camino del reconocimiento. Por último y, en tercer término como resultado de este doble movimiento y efecto del reconocimiento, se produce una exteriorización (Entäusserung) de tipo enajenadora. La Autoconciencia se extraña de su propia realidad.

\section{CONCLUSIÓN}

La Autoconciencia adquiere a través del reconocimiento la unidad del Yo y del nosotros trascendiendo al Selbst no sólo como individualidad vital, sino como eliminación definitiva de la simplicidad (Einzelnheit) y de la referencia

17 Siep matiza: "Con la lucha por el reconocimiento Hegel no quiere ofrecernos el proceso histórico de enemistad de comunidades armónicas, de la lucha entre partidos o clases y de su reconciliación en el concepto, sino integrar la teoría del derecho natural del antagonismo de lo 'natural' -es decir, de lo que no se reúne a través de contratos [o constituciones] (Verträge)- con la libertad del individuo en su concepción de la formación (Bildung) del espíritu”. Siep (1974), art. cit., p.390.

18 G.W. 9 (Phä), p.104, líneas 34-38. 
(Beziehung) de la Conciencia, en favor de la "relación" (Verhältniss). Esta es la diferencia fundamental entre las dos figuras: la tensión resuelta entra la referencia y la relación que sucede en ellas ${ }^{19}$. En el momento en que la Autoconciencia llega al reconocimiento se produce una adquisición de contenido en todo punto irrenunciable. De este modo, la presente figura puede desempeñar el papel positivo de la siguiente: la Razón y alcanzar así la cima de su contenido en el Espíritu.

El Espíritu es la figura perfecta en la que el momento del retorno se lleva a cabo sin obstáculos. Dicho momento es necesario para alcanzar el estrato del Saber absoluto ${ }^{20}$ en que se identifican la Sustancia y el contenido de la realidad sin resistencias.

19 El estudio de la referencia y la relación, así como sus implicaciones ontológicas las lleva a cabo Hegel en: G.W. 7 (Log) Jenaer Kritische Schriften II. Logik Metaphysik und Naturphilosophie. Ed. Cit., (1971). A este respecto también podemos ver el trabajo de R. Schäffer Die Dialektik und ihre besonderen Formen in Hegels Logik. Hegel Studien Beiheft n 45 Felix Meiner, Hamburg (2001). En especial, el Capítulo II que dedica a la Lógica de Jena (1804-5) en las pp.91-157.

20 Düsing nos aclara estos términos: "De este ser-otro regresa el Espíritu en sí [por lo que] él se contempla como la acción del Devenir que es lo-otro-de-sí (Sich-Anders-Werdens) y el Retorno en sí”. Düsing, K. "Idealistische Substanzmetaphysik. Probleme der Systementwicklung bei Schelling und Hegel in Jena”, Hegel Studien Beiheft, no 20 (1980), p.42. 
